\title{
Uso e Ocupação do Solo em Bacia Hidrográfica Urbana a Partir de Imagens Orbitais de Alta Resolução
}

\author{
Rafael Franco Vaeza ${ }^{1}$, Paulo Costa de Oliveira Filho ${ }^{2}$, \\ Adelena Golçalves Maia ${ }^{3}$, Atílio Antonio Disperati ${ }^{4}$ \\ ${ }^{1}$ Arco Ambiental Projetos e Consultoria \\ ${ }^{2}$ Departamento de Engenharia Ambiental, Universidade Estadual do Centro-Oeste - UNICENTRO-PR \\ ${ }^{3}$ Departamento de Engenharia Civil, Universidade Federal do Rio Grande do Norte - UFRN \\ ${ }^{4}$ Departamento de Engenharia Florestal, Universidade Estadual do Centro-Oeste - UNICENTRO-PR

\section{RESUMO} \\ Foram mapeadas sete classes de uso e cobertura do solo da composição urbana por meio de \\ imagens orbitais do satélite Quickbird para estudo de bacia hidrográfica situada em área urbana. \\ Foi objetivo deste estudo gerar uma Carta de Uso e Ocupação do Solo em nível detalhado da \\ Bacia do Arroio dos Pereiras, Irati-PR, as áreas das classes utilizadas e respectivos percentuais, \\ fornecendo subsídios a estudos sobre possíveis ocorrências de enchentes na região central do \\ Município de Irati, Paraná. Como resultado, foram obtidos os percentuais de 22,56\% para a \\ classe Florestas, 0,22\% para Lagoas, 9,68\% para Ruas e Calçadas, 4,84\% para Áreas Permeáveis \\ Dentro das Quadras, 5,73\% para Áreas Impermeáveis Dentro das Quadras, 10,53\% para \\ Telhados e 46,45\% para vegetação rasteira.
}

Palavras-chave: sensoriamento remoto, alta resolução espacial, bacia hidrográfica urbana.

\section{Land Cover and Usage in an Urban Drainage Basin Analyzed Through High Resolution Image Satellite}

\begin{abstract}
All classes of land cover and usage of an urban site have been mapped through 'Quickbird' image of $61 \mathrm{~cm}$ of space resolution for the study of a hydrologic basin. The objective of this study is to generate a detailed map of land cover and usage of the basin of "Arroio dos Pereiras" stream, located in Irati, State of Parana, Brazil, and also to quantify all the classes considered on the mapping. The acquired results will support other studies on possible flood occurrences in the central region of the city. The percentage results are as follows: $22.56 \%$ of forests, $0.22 \%$ of lagoons, $9.68 \%$ of paved streets and sidewalks, $4.84 \%$ of pervious area inside blocks, $5.73 \%$ of impervious area inside blocks, $10.53 \%$ of roofs and $46.45 \%$ of tripping vegetation.
\end{abstract}

Keywords: remote sensing, spatial high resolution, urban watershed. 


\section{INTRODUÇÃO}

A identificação e classificação do uso do solo são fundamentais no conhecimento do ambiente, assim como no desenvolvimento de técnicas voltadas para a obtenção e manutenção dessas informações. O conhecimento da distribuição espacial das várias formas de ocupação do espaço necessita de informações detalhadas, que possam ser obtidas com grande periodicidade, devido ao caráter extremamente dinâmico desse ambiente (Foresti \& Hamburger, 1995 apud Bittencourt et al., 2006).

Estudos em bacias hidrográficas podem utilizar as imagens orbitais de alta resolução espacial na obtenção de classes de uso e ocupação do solo. Essas imagens permitem a obtenção de resultados mais precisos na identificação dos mais diversificados elementos da composição urbana. É possível mapear e quantificar as mais variadas classes de uso do solo em bacia hidrográfica localizada em área urbana, onde a alta resolução das imagens passa a ser de fundamental importância para um estudo mais detalhado. À medida que a ocupação urbana na bacia aumenta, verifica-se um expressivo aumento das áreas impermeabilizadas, com isso o tempo de recorrência das precipitações tende a minorar. Ocorre redução das perdas por infiltração, aumento do volume e velocidade de escoamento superficial, e esse aumento gera problemas de drenagem, como é o caso de enchentes (Vaeza et al., 2008).

Silva et al. (2005) consideram essencial que a escolha da imagem e da metodologia de classificação do uso do solo deve ocorrer de acordo com as necessidades do usuário e com as características da região.

Segundo Centeno et al. (2003), grande parte dos modelos hidrológicos que tratam da drenagem urbana necessita conhecer a área impermeável e a modificação das condições de escoamento das bacias devido à ocupação do solo, pois o aumento de áreas impermeáveis aumenta o escoamento superficial.

Os trabalhos relacionados à interpretação do uso do solo de sub-bacias localizadas em áreas urbanas são mais recentes e necessitam de imagens de alta resolução espacial, como é o caso das imagens do sensor Quickbird a bordo do Satélite Quickbird II.

Uma bacia hidrográfica qualquer se constitui como a mais adequada unidade de planejamento para o uso e exploração dos recursos naturais, pois seus limites são imutáveis dentro do horizonte de planejamento humano, o que facilita o acompanhamento das alterações naturais ou introduzidas pelo homem na área. Assim, o disciplinamento do uso e da ocupação das terras da bacia hidrográfica é o meio mais eficiente de controle dos recursos hídricos que a integram.

As técnicas de sensoriamento remoto e de geoprocessamento tornaram-se ferramentas úteis e indispensáveis no monitoramento da dinâmica de uso e ocupação das terras, pelo fato de propiciar maior frequência na atualização de dados, agilidade no processamento e viabilidade econômica.

Collares (2000) ressalta que, com o advento de recursos de sensoriamento remoto mais aperfeiçoado, os levantamentos das informações tendem a ser mais precisos e rápidos e, com o avanço nos sistemas de comunicações via rede, deverá haver maior facilidade para disponibilização, troca de informações e atualizações de dados.

Segundo Feltran-Filho et al. (1989), o uso do solo nada mais é que a forma de como o solo está sendo utilizada pelo homem. Esse uso pode provocar alguns danos ao meio ambiente, como erosão intensa, inundações, assoreamento dos reservatórios e cursos d'água.

O desenvolvimento de um sistema para classificar dados sobre o uso da terra, obtidos a partir da utilização de técnicas de sensoriamento remoto, tem sido muito discutido. O tipo e a quantidade de informações sobre o uso da terra dependem da resolução espacial, radiométrica, espectral e temporal dos diferentes sistemas sensores utilizados. O tamanho da área mínima capaz de ser descrita como pertencente a uma determinada categoria (classe) de uso da terra depende da escala e resolução dos dados originais, além da escala de compilação e da escala final de apresentação.

Para Medeiros \& Petta (2005), a preocupação, cada vez mais frequente, sobre a forma e o tipo de ocupação do seu território tem levado os governos a se interessarem por estudos que abordem essa questão. Entende-se que pesquisas, análises e interpretações do uso e ocupação do solo e da dinâmica geoambiental colaboram, de maneira consistente, com o conhecimento aprofundado de uma região. 
Segundo Mendes \& Cirilo (2001), o impacto decorrente da alteração do uso do solo reflete-se em todos os componentes do ciclo hidrológico, como no escoamento superficial, na recarga dos aquíferos e na qualidade da água.

Amaral et al. (2007) utilizaram fotografias aéreas verticais de pequeno formato $(35 \mathrm{~mm})$, com escala aproximada de 1:5.000, para o estudo de uso e ocupação do solo em bacia hidrográfica e definiram as seguintes classes: Ruas e Calçadas, Área permeável dentro dos lotes, Área impermeável dentro dos lotes e Lagoas.

Pilz \& Strobl (2005) utilizaram ortofotografias aéreas digitais coloridas na escala 1:1000, para o estudo das superfícies impermeabilizadas em bacia hidrográfica e definiram as seguintes classes: Telhados, Terrenos Impermeabilizados e Não impermeabilizados.

Leukert (2005) utilizou fotografias aéreas digitais na escala 1:5.000 e no processo de classificação definiu as seguintes classes: Área verde, Área verde urbana e Área impermeável e em função das ocorrências em relação ao uso do solo na área de estudo.

$\mathrm{O}$ uso e manejo inadequados das terras e a falta de ações conservacionistas implicam em perdas significativas, de solo, matéria orgânica, nutrientes, biodiversidade, perdas com enchentes e, em especial, de água, prejudicando o equilíbrio dos sistemas hídricos em bacias hidrográficas. O levantamento do uso e cobertura da terra como parte de um diagnóstico ambiental é a primeira etapa para o planejamento conservacionista como estratégia para a reversão desse quadro.

O presente trabalho apresenta como objetivo um diagnóstico de uso e ocupação do solo em bacia hidrográfica urbana onde as classes foram definidas de acordo com a alta resolução das imagens utilizadas e com a temática envolvendo graus distintos de permeabilidade do solo.

\section{MATERIAL E MÉTODOS}

O estudo foi desenvolvido na bacia hidrográfica do Arroio dos Pereiras, localizada na área urbana do Município de Irati-PR, entre as coordenadas $(535090,7180689)$ e $(537231,7183819)$ do sistema UTM, fuso 22, ocupando uma área de $3,5 \mathrm{~km}^{2}$. Ela é do tipo "Bacia Fechada", termo usado para designar bacias sem exutório, com retenção do escoamento superficial nas áreas mais baixas, o que gera inundação. A delimitação da Bacia foi feita com uso da base cartográfica digital da área urbana do Município de Irati no sistema AutoCAD, através das curvas de nível.

Para a realização do estudo, foi utilizado um segmento de imagem multiespectral fusionada de $61 \mathrm{~cm}$ de resolução, cedida pela Prefeitura Municipal de Irati, obtida pelo sensor Quickbird a bordo do satélite norte americano Quickbird II. A imagem foi adquirida pelo Departamento de Geoprocessamento da prefeitura no ano de 2005, e o segmento de imagem utilizado constitui-se de um recorte do quadro urbano.

Como recurso de software, foi utilizado o Spring versão 4.3.3. Também foram utilizados os aplicativos Impima 4.3.3, e Scarta 4.3.3. para posterior confecção do mapa final.

Inicialmente, as bandas de imagem no formato TIFF foram transformadas em GRIB (formato matricial do Spring versão 4.3.3) no programa Impima, para serem processadas no aplicativo Spring. $\mathrm{Na}$ sequência, foi efetuado o recorte da imagem através de uma máscara vetorial dos limites da área da bacia, visando diminuir o tamanho do arquivo e otimizando o tratamento digital da imagem.

A referida imagem tinha originalmente resolução radiométrica de 11 bits e foi convertida para 8 bits, nível de informação utilizado pela versão do aplicativo em questão, fornecendo, portanto, alcance máximo de 256 tonalidades de cinza. A seguir, a imagem já obtida em forma de composição colorida com um bom nível de correção geométrica foi interpretada. Os trabalhos iniciais de interpretação de imagem, além de embasamento em literatura, foram importantes para que a definição das classes utilizadas no trabalho fosse direcionada aos objetivos da temática. As sete classes definidas foram: Florestas, Lagoas, Vegetação Rasteira, Telhados, Ruas e Calçadas, Áreas Permeáveis Dentro das Quadras, Áreas Impermeáveis Dentro das Quadras e telhados. Estas se apresentam caracterizadas na Tabela 1. Após a definição das classes de uso/ocupação do solo, executou-se a vetorização sobre tela de cada uma das classes através do módulo de edição vetorial do software Spring versão 4.3.3. O trabalho de campo 
Tabela 1. Descrição das classes de uso e ocupação do solo utilizadas.

Table 1. Description of classes of use and occupation of land used.

\section{Tipologia - Descrição}

\section{Fotografia ilustrativa}

Florestas: A cobertura florestal confere proteção ao solo contra o impacto direto das gotas de chuva, diminuindo a velocidade de escoamento superficial e favorecendo a infiltração de água no solo. As relações de equilíbrio existentes entre a vegetação primária e o solo, garantem o ideal funcionamento do ciclo hidrológico.

Lagoas: São de extrema importância para o ecossistema, pois, quando chove, a recarga do lençol freático é feita através delas, além de evitar as inundações com a absorção da água pelo solo. Corresponderam aos lagos e represas distribuídos por toda a bacia hidrográfica.

Vegetação rasteira: Abrange as pastagens, plantios e vegetação espontânea. Incluemse as coberturas residuais baixas, até rasteiras, representadas por glebas aparentemente desprovidas de cuidados e com cobertura do solo variável (campos sujos).

Ruas e calçadas: Fizeram parte da mesma classe devido a seus recobrimentos exercerem o mesmo papel dentro da bacia, que seria de áreas impermeabilizadas fora dos lotes, o que as tornam também responsáveis pelo escoamento superficial.

Áreas permeáveis dentro das quadras: Correspondem aos canteiros, hortas, gramados, jardins, etc. Ajudam na inflitração da água no solo, evitando o escoamento superficial.

Áreas impermeáveis dentro das quadras: Nestas áreas, os ladrilhos, azulejos e até mesmo áreas com pavimentação impedem a infiltração, causando o aumento do escoamento superficial e redução na recarga da água subterrânea.

Telhados: Possui o papel de conduzir a água da chuva até outros locais impermeabilizados e/ou permeabilizados, a água escoa por sua superfície e cai até o solo. 
correspondeu à etapa de checagem dos dados, no intuito de auxiliar no processo de interpretação da imagem. Procurou-se identificar, descrever e fotografar em campo, e detalhar as classes em campo para associação com a imagem de satélite. Ao final dos trabalhos de interpretação e vetorização, foi possível obter o mapa de uso e ocupação do solo, suas áreas e respectivos percentuais.

\section{RESULTADOS E DISCUSSÃO}

De acordo com os resultados apresentados na Figura 1 e na Tabela 2, a classe de vegetação rasteira é predominante, ocupando 46,45\% (164,10 ha) do total de 353,33 ha. Esta classe abrange as pastagens, plantios e vegetação espontânea. Incluemse as coberturas residuais baixas, até rasteiras, representadas por glebas aparentemente desprovidas de cuidados e com cobertura do solo variável (campos sujos).

$\mathrm{A}$ área com Florestas, que corresponde à floresta urbana mais densa, ocupa 22,56\% (79,71 ha) da área total. A cobertura florestal confere proteção ao solo contra o impacto direto das gotas de chuva, diminuindo a velocidade de escoamento superficial e favorecendo a infiltração de água no solo.

A classe Telhados foi a primeira a ser vetorizada em virtude de ser a de mais fácil identificação, por apresentar colorações, geometria e sombreamento

Tabela 2. Classes de uso e ocupação do solo e respectivas áreas em $\mathrm{km}^{2}$ e em percentuais em 2005 na Bacia no Arroio dos Pereiras.

Table 2. Use classes and land use and areas in $\mathrm{km}^{2}$ and in percentages in 2005 in the basin of the Pereiras river.

\begin{tabular}{lcr}
\multirow{2}{*}{ Classes } & \multicolumn{2}{c}{ Área ocupada } \\
\cline { 2 - 3 } & $\mathbf{k m}^{2}$ & $\%$ \\
\hline Lagoas & 0.007772 & 0,22 \\
Florestas & 0.797196 & 22,56 \\
Vegetação rasteira & 1.641 .096 & 46,45 \\
Ruas e calçadas & 0.341908 & 9,68 \\
$\begin{array}{l}\text { Áreas impermeáveis } \\
\text { dentro das quadras }\end{array}$ & 0.202511 & 5,73 \\
$\begin{array}{l}\text { Áreas permeáveis } \\
\text { dentro das quadras }\end{array}$ & 0.170905 & 4,84 \\
Telhados & 0.371922 & 10,53 \\
Total & 3.533 .310 & 100,00 \\
\hline
\end{tabular}

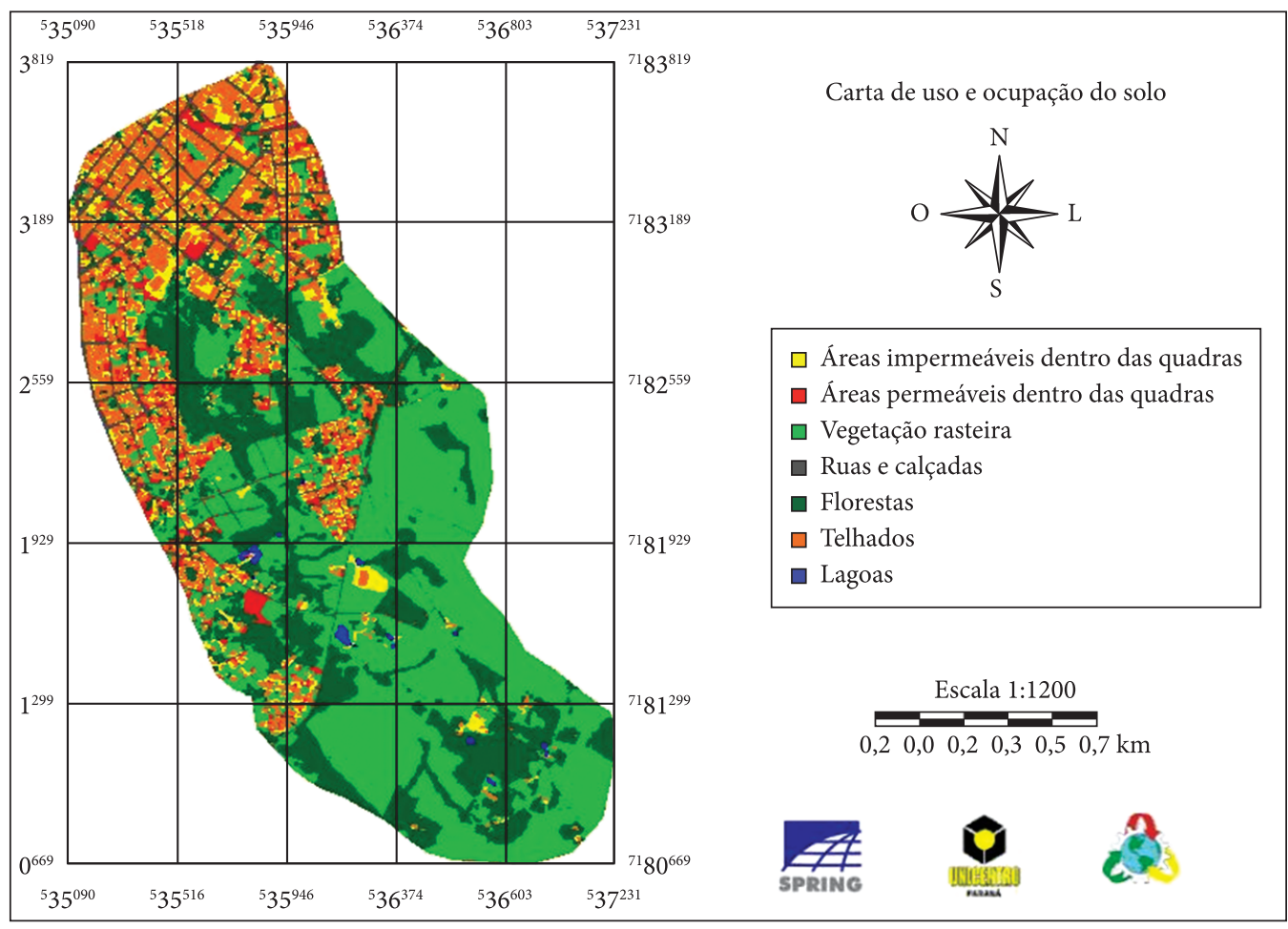

Figura 1. Carta de uso e ocupação do solo obtido da Área de Estudo Bacia Arroio dos Pereiras em 2005. Figure 1. Map of land use study area obtained from the Stream Basin in 2005. 
característicos. O telhado possui o papel de conduzir a água da chuva até outros locais impermeabilizados e/ou permeabilizados, a água escoa por sua superfície e cai até atingir o solo. Os telhados ocupam 10,53\% (37,19 ha) do total da bacia.

Ruas e Calçadas totalizam 9,68\% (34,19 ha) da área total da bacia e fizeram parte da mesma classe devido a seus recobrimentos exercerem o mesmo papel dentro da bacia, que seria de áreas impermeabilizadas fora dos lotes.

Áreas Impermeáveis Dentro das Quadras ocupam $5,73 \%$ (20,25 ha) da área total da bacia do Arroio dos Pereiras. Nestas áreas, a pavimentação impede a infiltração, causando o aumento do escoamento superficial e redução na recarga da água subterrânea.

As Áreas Permeáveis Dentro das Quadras ocupam 4,84\% (17,09 ha) da área total da bacia. Elas ajudam na infiltração da água no solo, evitando o escoamento superficial.

A classe Lagoas corresponde aos lagos e represas distribuídos por toda a bacia, abrangendo $0,22 \%$ (0,77 ha) de sua área.

Analisando os resultados percentuais encontrados, pode-se dizer que a bacia possui um bom estado de conservação, principalmente se levarmos em conta os percentuais de florestas e de vegetação rasteira. No entanto, a bacia, considerada como uma bacia hidrográfica urbana, possui ao sul e oeste uma região composta por chácaras e parques, não apresentando as características da ocupação urbana. Desta forma, se analisarmos somente os resultados numéricos, estes podem mascarar a condição de conservação e de impermeabilização da bacia.

A interpretação na tela do monitor foi realizada classe a classe, ou seja, o intérprete elaborou as vetorizações sem que se passasse para a classe seguinte antes de se efetuar todo o trabalho na anterior. Isto facilitou o trabalho devido ao acúmulo de informações na medida em que os problemas de distinção dos diferentes alvos iam aparecendo, melhorando a percepção do intérprete.

Os resultados deste trabalho serão de grande utilidade para pesquisas hidrológicas e de gestão de recursos hídricos na área de estudo. As informações referentes ao uso e ocupação de solo da bacia hidrográfica do Arroio dos Pereiras serão utilizadas na pesquisa referente ao estudo da ocorrência de enchentes na região central de Irati (PR), atualmente realizada.

\section{CONCLUSÕES}

Ao invés do uso de classificação automática, o processo de vetorização sobre tela apresentou uma alternativa para a classificação das imagens de alta resolução, devido à acentuada confusão espectral na área do estudo.

As classes de uso e ocupação do solo definidas no estudo da bacia hidrográfica em questão são bastante relacionadas ao processo de compactação do solo, pois este está intimamente ligado aos níveis de impermeabilização na área da bacia hidrográfica.

Conforme os dados de uso e ocupação do solo, podemos constatar que a Classe vegetação rasteira é predominante na bacia do Arroio dos Pereiras, em função da bacia se caracterizar por duas partes bem distintas de uso e ocupação: uma bem urbana e com alta densidade demográfica, e outra com densidade bem menor, onde predomina a vegetação rasteira.

A Bacia Arroio dos Pereiras não apresenta um estado de conservação tão bom quanto os números encontrados apontam. Isto porque apresenta duas regiões distintas e bem definidas, sendo uma região composta por chácaras e parques, não apresentando as características da ocupação urbana, e outra com as características típicas de composição urbana.

\section{AGRADECIMENTOS}

Os autores agradecem à Prefeitura Municipal de Irati a cessão das imagens de satélite, fundamentais a este estudo, e à Fundação Araucária a bolsa de iniciação científica cedida ao aluno Rafael Vaeza.

\section{STATUS DA SUBMISSÃO}

Recebido: 05/08/2008 


\section{AUTOR(ES) PARA CORRESPONDÊNCIA}

\section{Paulo Costa de Oliveira Filho}

Depto de Engenharia Ambiental, Universidade Estadual do Centro-Oeste UNICENTRO-PR, Campus de Irati, PR 153, Km 07, Riozinho, CP 21, CEP 84500-000, Irati, PR, Brasil e-mail: paulocostafh@gmail.com

\section{REFERÊNCIAS}

Amaral RF, Ferreira Jr AV, Henriques APM. Aplicações em estudos ambientais. In: Disperati AA, Amaral RF, Schuler CAB. Fotografias aéreas de pequeno formato: aplicações ambientais. Guarapuava: UNICENTRO, 2007. cap. 7, p. 179-218.

Bittencourt LFF, Batista GT, Catelani CS. Sensoriamento remoto aplicado ao estudo de ocupação de solo de mata ciliar do rio Paraíba do Sul no município de Caçapava. In: Anais do I Seminário de Sensoriamento Remoto e Geoprocessamento do Vale do Paraíba - GEOVAP; 2006; Taubaté, Brasil. UNITAU; 2006. p. 89-99.

Centeno JAS, Antunes AFB, Trevisan S, Correa F. Mapeamento de áreas permeáveis usando uma metodologia orientada a regiões e imagens de alta resolução. Revista Brasileira de Cartografia 2003; 55(1):48-56.

Collares EG. Avaliação de alterações em redes de drenagem de microbacias como subsídio ao zoneamento geoambiental de bacias hidrográficas: aplicação na bacia hidrográfica do Rio Capivari - SP [tese]. São Carlos SP: Escola de Engenharia de São Carlos, USP; 2000.
Feltran-Filho AF, Lima SC, Rosa R. Mapeamento do uso do solo no município de Uberlândia - MG, através de imagens TM/LANDSAT. Sociedade \& Natureza 1989; 1(2):127-145.

Leukert L. Utilização de dados SIG para a obtenção de objetos. In: Blaschke T, Kuk H. Sensoriamento remoto e SIG avançados. São Paulo: Oficina de Textos; 2005. cap. 14 p.139-146.

Medeiros CNE, Petta RA. Exploração de imagens de satélite de alta resolução visando o mapeamento do uso e ocupação do solo. In: Anais do Simpósio Brasileiro Sobre Sensoriamento Remoto - SBSR, Goiânia; 2005. INPE; 2005. p. 2709-2716.

Mendes CAB, Cirilo JA. Geoprocessamento em recursos hídricos: princípios, integração e aplicação. Porto Alegre: ABRH, 2001. 536 p.

Pilz H, Strobl J. Análise de impermeabilização com base em ortofotografias aéreas coloridas digitais através de processamento de imagens orientadas a objetos. In: Kux $\mathrm{H}$, Blaschke T. Sensoriamento remoto e SIG avançados. São Paulo: Oficina de Textos; 2005.

Silva MKA, Brito JLS, Rosa R. Mapeamento do uso do solo no município de Pedrinópolis - MG. In: Anais do XII Simpósio Brasileiro de Sensoriamento Remoto; 2005; Goiânia, Brasil. INPE; 2005. p. 285-291.

Vaeza RF, Oliveira-Filho PC, Disperati AA, Maia AG. Uso e ocupação do solo a partir de imagens orbitais de alta resolução para estudo em bacia hidrográfica em área urbana. In: Anais do XIX Seminário de Pesquisa; Anais da XIV Semana de Iniciação Científica; 2008; Irati. Irati, PR: Universidade Estadual do Centro-Oeste - UNICENTRO; 2008. 